\title{
Evaluation of the efficacy of ${ }^{99 \mathrm{~m}} \mathrm{Tc}$-Infecton, a novel agent for detecting sites of infection
}

\author{
A V Hall, K K Solanki, S Vinjamuri, K E Britton, S S Das
}

\begin{abstract}
Aims-To determine the sensitivity and specificity of ${ }^{99 \mathrm{~m}} \mathrm{Tc}$-Infecton (Infecton), a novel ciprofloxacin based imaging agent, in detecting sites of infection.

Methods-Ninety patients thought to be suffering from a variety of infections were administered 300-400 $\mathrm{MBq}$ of Infecton intravenously. Whole body images were taken one and four hours later. Appropriate specimens were taken for microbiological investigations. Statistical analysis was performed using a computer statistical package.

Results-Ninety eight Infecton images were produced. Forty one of these were positive, including three false positives, where the patients had non-infective conditions. Fifty seven negative images were obtained, of which 41 were true negatives and 16 were false negatives, having definite evidence of infection. Thus, Infecton imaging has a sensitivity of $\mathbf{7 0 . 3 \%}$ and a specificity of $\mathbf{9 3 . 1 \%}$ for detecting infective foci. The positive and negative predictive values were $92.6 \%$ and $71.9 \%$, respectively. Conclusion-Infecton imaging is a new diagnostic tool that is specific for detecting sites of bacterial infection in the body. The high positive predictive value displayed by the technique is clinically important because a positive image strongly supports a diagnosis of bacterial infection. A negative result does not rule out an infection, and may be a result of previous or current antibiotic treatment and/or infection with organisms that do not take up Infecton. Infecton imaging has major advantages over well established imaging techniques, including radiolabelled leucocytes, and may prove to be a superior method for localising bacterial infections.

(f Clin Pathol 1998;51:215-219)
\end{abstract}

Keywords: infecton; imaging; bacterial infection; ciprofloxacin

The diagnosis of deep seated infection can be a challenging problem. Imaging techniques such as $x$ rays, computed tomography (CT), magnetic resonance imaging (MRI), and ultrasonography might be helpful but are not specific for infection. The introduction of radiopharmaceuticals has enhanced infection imaging, as it relies on the demonstration of pathophysiological changes, rather than gross changes in structure.
Radiolabelled leucocyte imaging (WBC imaging) is currently the main method used for imaging infection. Neutrophils migrate to the site of infection through diapedesis and chemotaxis. ${ }^{1}$ They can be labelled with indium $111\left({ }^{111} \mathrm{In}\right)$, using either oxine or tropolone as a chelating agent, or technetium $99\left({ }^{99 \mathrm{~m}} \mathrm{Tc}\right)$, using hexamethylpropyleneamineoxime (HMPAO) as a chelating agent. The technique has the disadvantage that although it is very specific for detecting inflammatory foci, it does not distinguish between infective and non-infective inflammatory conditions. ${ }^{2}$ Imaging with radiolabelled antibodies, ${ }^{3}$ chemotactic peptides (which bind to neutrophil surface receptors), ${ }^{4}$ nanocolloids, ${ }^{5} \quad$ liposomes,${ }^{6}$ and streptavidin-biotin $^{7}$ are under investigation, but again most of these are not infection specific agents.

We have developed a novel radiopharmaceutical, ${ }^{99 \mathrm{~m}} \mathrm{Tc}$-Infecton (Infecton), based on the 4-fluoroquinolone broad spectrum antibiotic ciprofloxacin. Following intravenous injection, ciprofloxacin is widely distributed in the body and is excreted via the kidneys. The microbiological activity is mediated by inactivation of the bacterial DNA gyrase. This results in the retention of the agent at sites of active bacterial infection. We have demonstrated that Infecton is taken up by a wide range of live (but not dead) bacteria in vitro, and in animal experiments this agent is taken up only by bacterial, not sterile, abscesses. A preliminary study indicated that Infecton imaging was more specific in localising bacterial infection than WBC imaging. ${ }^{8}$ We present data on the efficacy of Infecton imaging in the first 90 patients with suspected infective disorders to have undergone such investigation, and discuss in greater detail the microbiological aspect of the study.

\section{Methods}

Ninety patients with suspected infective conditions were entered into the study. The study was approved by the local ethics committee and informed consent was obtained from each patient.

The preparation of Infecton together with the radiochemistry is described elsewhere. ${ }^{9}$ Briefly, $2 \mathrm{mg}$ of ciprofloxacin is mixed with $4 \mathrm{mg}$ of formamidine sulphonic acid and $1000 \mathrm{MBq}$ of sodium pertechnetate (technetium) solution, and boiled at $100^{\circ} \mathrm{C}$ for 10 minutes (the antibiotic is not affected by boiling). The mixture is sterilised and the unbound technetium removed by filtration through a sephadex column attached to a $0.5 \mu \mathrm{m}$ filter.
Accepted for publication 20 January 1998 


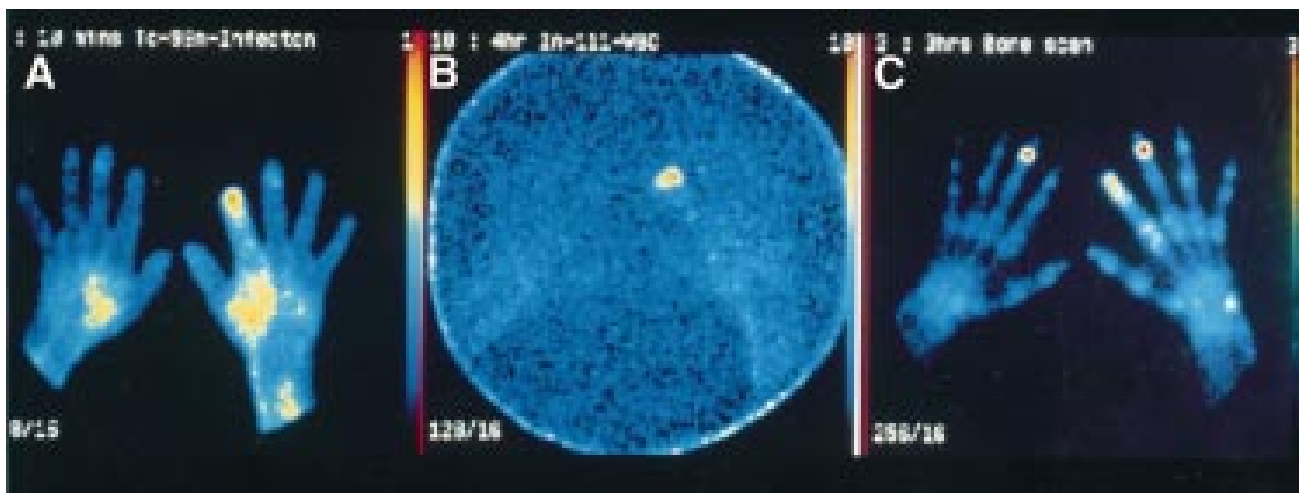

Figure 1 Osteomyelitis of the right index finger. $(A){ }^{99 m}$ Tc-Infecton image at 10 minutes; (B) ${ }^{111}$ In labelled leucocyte image at four hours; $(C)^{99 m}$ Tc methylene diphosphonate bone scan image at three hours.

Between 370 and $400 \mathrm{MBq}$ of Infecton was injected intravenously over 40 seconds. Anterior and posterior whole body static images were acquired at approximately one and four hours, and occasionally 24 hours after injection.

CRITERIA FOR INTERPRETATION OF INFECTON IMAGES

(1) All images were reviewed by three nuclear medicine physicians on a majority basis. Sequential and four hour images were mandatory for inclusion and interpretation.

(2) Only one site of infection was considered for each patient at each visit.

(3) In the case of multiple visits, individual assessment for each visit was necessary for inclusion.

(4) The criteria for diagnosis of infection was based on the Centers for Disease Control and Prevention (CDC) definitions for nosocomial infections. ${ }^{10} \mathrm{~A}$ patient was considered to have definite infection if the CDC criteria were met. A diagnosis of probable infection was made if the CDC criteria were not met but the patient was treated as infected by the attending physician.

(5) A true positive result was one in which the imaging showed an area of abnormal uptake of the agent together with other evidence of focal infection at the same site within five days of the image.

(6) A false positive result was one in which the image findings were abnormal but there was no evidence of infection at the same site within five days of the image.
(7) A true negative result was one in which imaging was negative and there was no evidence of focal infection within five days of imaging. This included patients whose infection had responded to antibiotic treatment at the time of imaging.

(8) A false negative result was one in which the imaging showed no abnormality but there was other evidence of focal infection within five days of imaging.

Susceptibility testing of bacteria to ciprofloxacin was performed using standard methods. ${ }^{11}$

Statistical analysis was performed on a computer using the statistical package for Social Sciences Software (SPSS Inc, Chicago, Illinois, USA).

\section{Results}

Ninety patients, 40 women and 50 men (mean age 51.5 years, age range $18-82$ years) were evaluable. Ninety eight Infecton images were performed, yielding 41 positive and 57 negative images. No adverse reactions occurred following administration of Infecton.

The normal Infecton image shows high uptake by the kidneys, with excretion to the urinary bladder, moderate uptake by the liver and spleen, and no uptake by bone, bone marrow, or other soft tissues. Early images predominantly show bloodpool activity, which is reduced in the delayed images. The gall bladder may be seen occasionally and some bowel activity may occur in the delayed images.

Table 1 Results of Infecton imaging according to type of suspected infection

\begin{tabular}{|c|c|c|c|c|c|}
\hline Suspected infective condition * & $\begin{array}{l}\text { True } \\
\text { positive }\end{array}$ & $\begin{array}{l}\text { False } \\
\text { positive }\end{array}$ & $\begin{array}{l}\text { True } \\
\text { negative }\end{array}$ & $\begin{array}{l}\text { False } \\
\text { negative }\end{array}$ & Total \\
\hline Osteomyelitis & 7 & 1 & 7 & 4 & 19 \\
\hline Septic arthritis & 1 & 2 & 3 & 1 & 7 \\
\hline Skin and soft tissue infection & 6 & 0 & 2 & 1 & 9 \\
\hline Surgical wound infection & 12 & 0 & 5 & 0 & 17 \\
\hline Pneumonia & 0 & 0 & 1 & 3 & 4 \\
\hline Lower respiratory tract infection excluding pneumonia & 1 & 0 & 2 & 0 & 3 \\
\hline Infective endocarditis & 2 & 0 & 2 & 3 & 7 \\
\hline Intravascular device infection & 1 & 0 & 2 & 0 & 3 \\
\hline Urinary tract infection & 2 & 0 & 3 & 0 & 5 \\
\hline Intracranial infection & 0 & 0 & 3 & 0 & 3 \\
\hline Gastro intestinal tract infection & 1 & 0 & 3 & 0 & 4 \\
\hline Intra-abdominal infection & 1 & 0 & 2 & 0 & 3 \\
\hline Reproductive tract infection including pelvic abscesses & 3 & 0 & 0 & 1 & 4 \\
\hline Systemic infection & 0 & 0 & 4 & $1 \dagger$ & 5 \\
\hline Other & $1 \neq$ & 0 & $2 \$ 9$ & $2^{\star \star \star+十}$ & $5 \ddagger$ \\
\hline Total & 38 & 3 & 41 & 16 & 98 \\
\hline
\end{tabular}

^According to CDC criteria; †Patient had disseminated listeriosis; $¥$ Psoas abscess; $§$ Thyroid disease; $₫$ Sinusitis; ${ }^{\star \star}$ Ischiorectal abscess; ††Paravertebral abscess. 


\author{
Figure 2 Osteomyelitis of \\ the sternum following \\ coronary artery bypass \\ surgery. $(A)^{99 m} T c$ \\ hexamethylpropylene- \\ amineoxime labelled \\ leucocyte images at three \\ hours; (B) ${ }^{99 m}$ Tc-Infecton \\ images at one hour. ANT, \\ anterior; $L A O$, left anterior \\ oblique; RAO, right anterior \\ oblique.
}

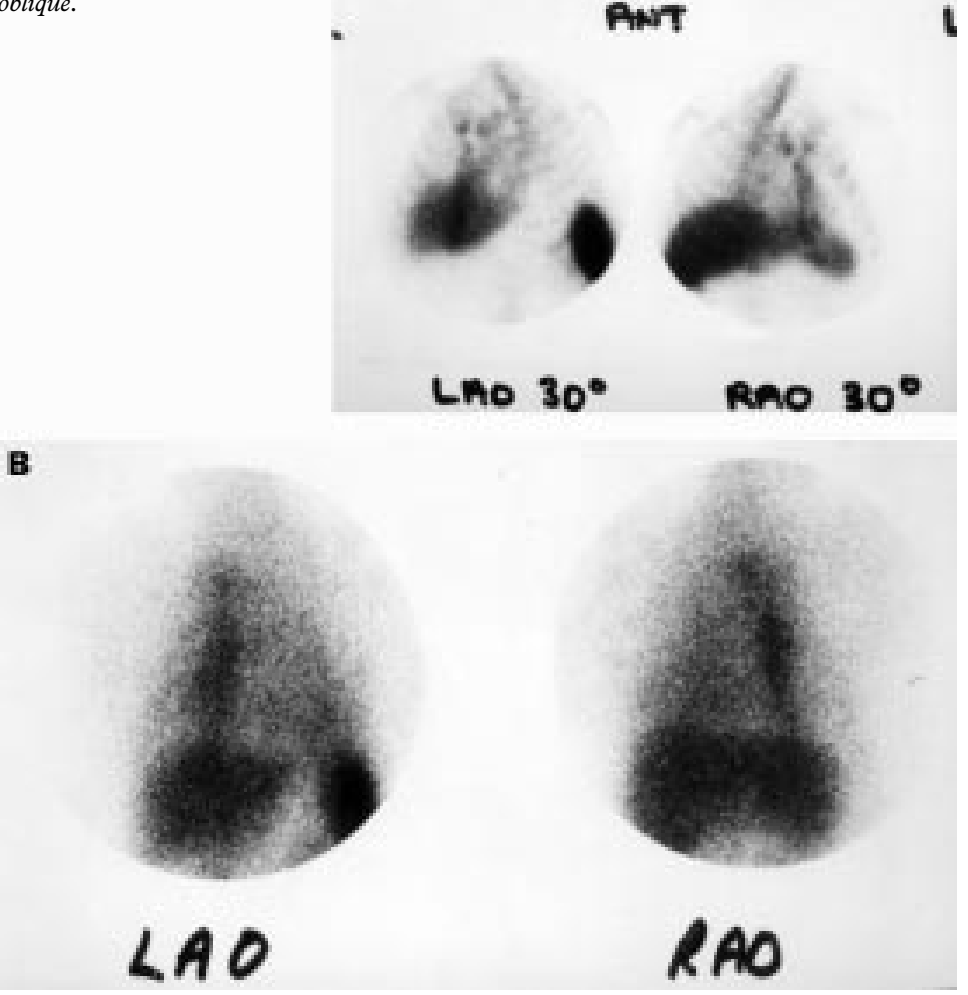

In an abnormal (positive) Infecton image, in addition to the normal distribution of Infecton, there is diffuse but intense uptake at sites of bacterial infection. This is well illustrated in figs 1 and 2, which are from patients with osteomyelitis of the right index finger and osteomyelitis of the sternum following coronary artery bypass surgery, respectively. In fig 1 , the bone scan shows high uptake in the distal interphalangeal joints of both third fingers, due to arthritis, and uptake in the distal right index finger, related to osteomyelitis. The ${ }^{111}$ In WBC imaging shows a focal area of increased uptake only in the index finger. In contrast, the Infecton scan shows high uptake
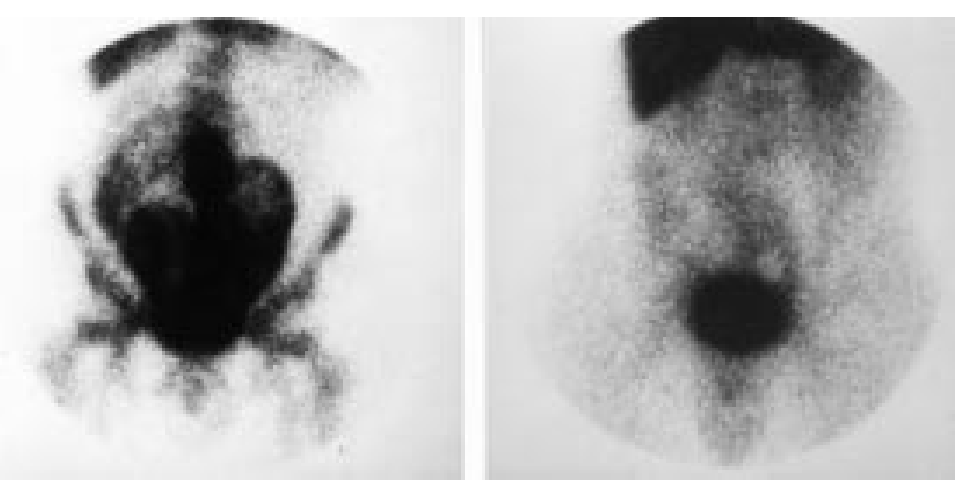

Figure 3 Sterile pouchitis. (Left) ${ }^{99_{m}}$ Tc hexamethylpropyleneamineoxime labelled leucocyte image at three hours; (right) ${ }^{99 m}$ Tc-Infecton image at one hour. in the right index finger, with a more diffuse pattern than the WBC imaging, because the living bacteria are around the site of pus with extension proximally. Because the image is early, vascular activity is seen in both wrists. In fig 2A (from the patient with sternal osteomyelitis) the ${ }^{99 \mathrm{~m}}$ Tc HMPAO labelled WBC imaging demonstrates increased uptake in the sternum, ribs, liver, spleen, and sternoclavicular points. The site of infection cannot be distinguished from the marrow activity. By comparison, Infecton imaging shows high uptake in the sternum. As Infecton is not taken up by the bone marrow, this represents active bacterial infection of the sternum, confirmed microbiologically. The negative Infecton imaging result in noninfective inflammatory conditions is well illustrated by the images obtained from a patient with sterile pouchitis (fig 3). In anterior views of the abdomen, ${ }^{99 \mathrm{~m}}$ Tc HMPAO labelled WBC imaging shows intense uptake in the lower abdomen in loops of ileum and in the ileo-anal Koch's pouch, in addition to the marrow uptake in the pelvis. Infecton imaging, in contrast, demonstrates activity in the liver, spleen, and bladder. The site of the loops of bowels appears as a defect in uptake. The lack of uptake indicates no bacterial infection in spite of the intense inflammation shown by WBC imaging. Microbiological investigations were negative.

A detailed analysis of the results of Infecton imaging according to the type of suspected infective condition is presented in table 1 . Table 2 summarises the results of Infecton imaging in terms of certainty of diagnosis of infection, while table 3 shows the type of organisms grown from culture positive patients.

\section{INFECTON IMAGE POSITIVE}

Of the 41 positive Infecton images, three were false positives. These were patients with rheumatoid arthritis of the hands, psoriatic arthritis of the hands, and non-union of a wrist fracture. Thirty four patients had definite infections according to CDC criteria. Four patients did not fit the CDC criteria but had physician diagnosis of infection on clinical grounds alone: culture negative cellutitis (one), septic arthritis (two), and non-union fracture of the wrist with Pseudomonas aeruginosa isolated from tissue deep to the skin (one).

Only 23 of the $38(60 \%)$ clinically infected patients had positive microbiology. Ten patients had skin and soft tissue infections (six of which were surgical wound infections) and nine of these were culture positive. Nine patients had osteomyelitis, four microbiologically proved. Four patients, all culture positive, had intra-abdominal sepsis. Four patients had infected surgical prostheses and three had septic arthritis, but cultures were negative. Two patients had infective endocarditis, one microbiologically proved. There was one each of psoas abscess, pulmonary abscess, urinary tract infection, and infected non-union of a fracture (all culture positive), and intravascular catheter and uterine infection (both culture negative). 
Table 2 Patient infection status and results of infecton imaging

\begin{tabular}{|c|c|c|c|}
\hline \multirow[b]{2}{*}{ Infection status } & \multicolumn{2}{|c|}{${ }^{99_{m}} T c-I n f e c t o n$ image } & \multirow[b]{2}{*}{ Total } \\
\hline & Positive & Negative & \\
\hline Uninfected & 3 & 41 & 44 \\
\hline Definite infection microbiology positive & 22 & 14 & 36 \\
\hline Definite infection microbiology negative & 12 & 1 & 13 \\
\hline Probable infection microbiology positive & 1 & - & 1 \\
\hline Probable infection microbiology negative & 3 & 1 & 4 \\
\hline Total & 41 & 57 & 98 \\
\hline
\end{tabular}

Table 3 Organisms isolated from culture positive patients

\begin{tabular}{lll}
\hline Organism & Number & Site of suspected infection \\
\hline Staphylococcus aureus & 18 & $\begin{array}{l}\text { Spine (3), upper limb (1), lower limb (1), } \\
\text { skin and soft tissue (7), pulmonary (1), } \\
\text { abdomen (1), heart (3), sacroiliac joint (1) }\end{array}$ \\
$\begin{array}{lll}\text { Methicillin resistant Staph aureus } & 4 & \text { Lower limb (2), skin and soft tissue (2) } \\
\text { Staphylococcus epidermidis } & 1 & \text { Heart (1) } \\
\text { Streptococcus pyogenes } & 1 & \text { Skin and soft tissue (1) } \\
\text { Enterococcus faecalis } & 1 & \text { Pelvis (1) } \\
\text { Streptococcus milleri } & 2 & \text { Skin and soft tissue (1), pulmonary (1) } \\
\text { Viridans streptococci } & 2 & \text { Heart (2) } \\
\text { Escherichia coli } & 5 & \text { Pelvis (1), skin and soft tissue (2), } \\
\text { usinary tract (1), intravascular device (1) } & & \text { Sternum (1), upper limb (1) } \\
\text { Clostridium difficile } & 2 & \text { Abdomen (1) } \\
\text { Listeria monocytogenes } & 1 & \text { Disseminated disease (1) } \\
\text { Mycobacterium tuberculosis } & 1 & \text { Skin and soft tissue (1), pulmonary (1), } \\
\text { disseminated disease (1) }\end{array}$ \\
$\begin{array}{l}\text { Rhodococcus equi } \\
\text { Multiple organisms }\end{array}$ & 3 & Indwelling vascular device (1) \\
\hline
\end{tabular}

Table 4 Ciprofloxacin sensitivity and ${ }^{99 m} T c$-Infecton imaging results

\begin{tabular}{|c|c|c|c|c|}
\hline \multirow[b]{2}{*}{ Organism } & \multicolumn{2}{|c|}{ Ciprofloxacin sensitive } & \multicolumn{2}{|c|}{ Ciprofloxacin resistant } \\
\hline & $\begin{array}{l}\text { Positive } \\
\text { image }\end{array}$ & $\begin{array}{l}\text { Negative } \\
\text { image }\end{array}$ & $\begin{array}{l}\text { Positive } \\
\text { image }\end{array}$ & $\begin{array}{l}\text { Negative } \\
\text { image }\end{array}$ \\
\hline Staphylococcus aureus & 3 & 6 & - & - \\
\hline Methicillin resistant Staph aureus & - & - & 3 & 1 \\
\hline Viridans streptococci & - & 1 & - & - \\
\hline Escherichia coli & 1 & 1 & 2 & - \\
\hline Pseudomonas aeruginosa & 1 & - & 1 & - \\
\hline
\end{tabular}

Table 5 Influence of antibiotic treatment on Infecton imaging

\begin{tabular}{lll}
\hline & Positive & Negative \\
\hline Patients on antibiotics (n) & 31 & 21 \\
Total infected patients (n) & 38 & 16 \\
Total patients in group (n) & 41 & 57 \\
Infected patients on antibiotics (\%) & 81.5 & 81 \\
Duration of treatment (where known) & & \\
$\quad$ Range (days) & $2-60$ & $3-46$ \\
Mean (days) & 14.12 & 13.6 \\
\hline
\end{tabular}

INFECTON IMAGE NEGATIVE

Of the 57 patients with a negative result, 41 were uninfected. However, 15 were infected according to CDC criteria, and these are false negative results. One patient did not fit the CDC definitions but was treated as clinically infected by the attending physician. Fourteen of the $16(88 \%)$ clinically infected patients had microbiologically proved infections.

From these results it can be calculated that Infecton imaging has a specificity of $93.1 \%$ and a sensitivity of $70.3 \%$ for detecting infective foci. The positive and negative predictive values are $92.6 \%$ and $71.9 \%$, respectively.

SUSCEPTIBILITY OF BACTERIAL ISOLATES TO CIPROFLOXACIN

Ciprofloxacin susceptibility testing results were available for 20 of the 43 organisms isolated (it is not our normal laboratory practice to test the other organisms isolated for susceptibility to this antibiotic). Thirteen were susceptible and seven were resistant to this antibiotic. Table 4 shows the results of ciprofloxacin susceptibility testing and the corresponding Infecton imaging results.

RELATION TO ANTIBIOTIC TREATMENT

Overall, 31 of the $38(81.5 \%)$ infected patients with a positive Infecton imaging result were on antibiotics at the time of imaging. In contrast, of the 57 patients with negative imaging result, 16 were infected, and 13 of these $(81 \%)$ were on antibiotics when imaged (table 5). There was no significant difference between the two groups with respect to antibiotic treatment ( $\mathrm{p}>0.05)$.

\section{Discussion}

The results demonstrate that when injected into patients, Infecton accumulates at sites of infection in sufficient amounts to be imaged scintigraphically. The main factor in Infecton imaging is the uptake of the radiolabelled antibiotic by bacteria, which is distinct from its antibacterial activity. Bacteria resistant to ciprofloxacin can still take up Infecton if the resistance is mediated only through DNA gyrase alteration (the most common mechanism). Microorganisms whose cell membranes are impermeable to ciprofloxacin, whether through innate or acquired mechanisms, fail to bind Infecton. Hence, infections with these organisms would not be amenable to imaging by this novel technique.

Neutrophils and activated macrophages can take up ciprofloxacin, ${ }^{12}$ although intracellular retention is less prolonged compared with the newer macrolides such as azithromycin. We have very little evidence that the uptake of Infecton by neutrophils and activated macrophages is an important factor in Infecton imaging as: (1) in animal experiments, Infecton is taken up only by bacterial but not sterile abscesses; (2) non-infective inflammatory conditions, such as ulcerative colitis and Crohn's disease are negative by Infecton imaging but positive by WBC imaging; and (3) preliminary in vitro results indicate that compared with bacteria, human white blood cells exhibit either no uptake or markedly reduced uptake of Infecton.

Ideally, we would have used culture proved cases to determine the efficacy of Infecton imaging. However, reliance on culture as gold standard would have excluded many of our patients who were infected but were culture negative for a variety of reasons, antibiotic therapy being the principal one, or could not produce a sample for culture. Therefore, the diagnosis of infection was made on the basis of the CDC criteria referred to earlier, and the efficacy of Infecton imaging was assessed accordingly.

The sensitivity and specificity of Infecton imaging were $70.3 \%$ and $93.1 \%$, respectively. The high positive predictive value $(92.6 \%)$ is of practical importance, as a positive Infecton image confirms a diagnosis of bacterial infection with a high degree of certainty. Only three 
patients with chronic inflammatory diseases gave false positive results (see below) and 41 "normal" patients were correctly negative, which is very reassuring. However, a negative result does not rule out infection. One of the most important reasons for the low sensitivity is antibiotic treatment, resulting in fewer viable bacteria that take up Infecton. By the time Infecton imaging was performed, many of our patients were on antibiotic therapy, with good clinical response. Therefore, negative Infecton images in these situations should be regarded as true negatives. Other reasons for the low sensitivity include infection in protected sites, as in endocarditis (see below), and infection with organisms that do not take up ciprofloxacin. Infective endocarditis may be particularly difficult to image. Three of the seven patients gave false negative images. Antibiotics have difficulty in penetrating vegetations on heart valves. The uptake of antimicrobials by bacteria at such sites may be limited further by the fact that a large proportion of microorganisms in vegetations display stationary phase growth, with reduced metabolic activity. In addition, the quantity of ciprofloxacin $(2 \mathrm{mg}$ ) in Infecton is very small. Imaging early on in the disease, imaging 24 hours after injection of Infecton, and increasing the amount of ciprofloxacin present in Infecton may be required to overcome the problem of low sensitivity of Infecton imaging.

Overall, antibiotic therapy did not significantly affect the results of Infecton imaging. However, larger studies looking specifically at this important aspect are required, with images taken before, during, and after antibiotic therapy, before firm conclusions can be made.

Serial imaging of two patients, one with culture negative osteomyelitis of the thumb and the other with Rhodococcus equi indwelling vascular catheter infection, demonstrated conversion of positive to negative images with successful therapy. In contrast, imaging remained positive in patients with persistent Pseudomonas aeruginosa sternal wound infections. Further studies are necessary to ascertain whether Infecton imaging might be useful in monitoring responses to antimicrobial therapy.

Seven patients with chronic inflammatory conditions were studied. Four patients (three with inflammatory bowel disease and one with rheumatoid arthritis) were negative by Infecton imaging. However, imaging was positive in three, including one patient with rheumatoid arthritis. The reasons for these false positive results are not clear but might result from uptake of ciprofloxacin by white blood cells. ${ }^{12}$ It has also been postulated that certain chronic inflammatory diseases such as rheumatoid arthritis may have an infectious aetiology. Our recent experience is that most of the occasional false positive images seen at four hours in chronic non-infective inflammatory disorders become negative when imaged at 24 hours.

Three patients with tuberculosis were included in the study. Two had pulmonary infections and were negative by Infecton imaging but one (with psoas abscess) was positive. Ciprofloxacin does have antimycobacterial activity in vitro. However, the very slow growth rate of these bacteria may result in an insufficient uptake of and, consequently, an unreliable imaging result with the current formulation of Infecton.

The number of individual bacterial species isolated from patients in the study was too small to draw firm conclusions regarding the efficacy of Infecton imaging in detecting infection due to specific pathogens. Such studies are currently in progress. Similarly, larger multicentre studies are in progress to define the role of Infecton imaging in specific types of infections, such as endocarditis, intravascular line infections, prosthetic joint infections, empyema, and pelvic inflammatory disease.

In a comparative study in 56 patients with presumed infection, Infecton imaging demonstrated similar sensitivity $(84 \%)$ and specificity $(96 \%)$. In contrast, white cell imaging had similar sensitivity $(81 \%)$ but lower specificity $(77 \%) .{ }^{8}$ In addition to being more specific for detecting bacterial infections, Infecton imaging has other important advantages over white cell imaging, namely: (1) it is simpler and cheaper to prepare; (2) it does not involve handling patients' blood with the associated hazards of blood borne infections, such as human immunodeficiency virus and hepatitis B and C; and (3) it does not depend on the patient's white cell count and, thus, can be used to image infections in neutropenic patients.

The technique of radiolabelling antibiotics has enormous potential for diagnostic use. Future developments include radiolabelling of antifungal, antiprotozoal, and anti-anaerobic agents, in addition to other antibiotics with different spectra of activity from ciprofloxacin. With modification, it may also prove to be a novel and powerful tool for studying the pharmacokinetics of antimicrobial agents.

1 Datz FL. The current status of radionuclide infection imaging. In: Freeman LM, ed. Nuclear medicine annual. New York: Raven Press, 1993:47-76.

2 Datz FL. Indium-111-labelled leucocytes for the detection of infection: current status. Semin Nucl Med 1994; 24: $92-109$.

3 Fischman AJ, Rubin RH, White AA, et al. Localisation of Fc and Fab fragments of non-specific polyclonal IgG at focal
sites of inflammation. $\mathcal{F}$ Nucl Med 1990;31:1199-205.

4 Fischman AJ, Pike MC, Kroon D, et al. Imaging focal sites of bacterial infection in rats with Indium-111 labelled chemotactic peptide analogues. $\mathcal{F}$ Nucl Med 1991;32:48391 .

5 Streule K, De Shriver M, Fridrich R. ${ }^{99 \mathrm{~m}}$ Tc-labelled HSA-nanocolloid versus ${ }^{111}$ In oxine-labelled granulocytes in detecting skeletal septic process. Nucl Med Commun 1988;9:59-67.

6 Morgan JR, Williams LA, Howard CB. Technetium-labelled liposome imaging for deep seated infection. Br $\mathcal{F}$ Radiol 1985;58:35-9.

7 Rusckowski M, Paganelli GM, Hnatowich DJ, et al. Imaging infection/inflammation in patients with streptavidin and radiolabelled biotin. Preliminary observations. $₹ \mathrm{Nucl}$ Med 1992; 33:924.

8 Vinjamuri S, Hall AV, Solanki KK, et al. Comparison of $99 \mathrm{mTc}$-Infecton imaging with radiolabelled white cell maging in the evaluation of bacterial infection. Lancet 1996;347:233-5.

9 Solanki KK, Bomanji J, Siraj Q, et al. Tc99m Infecton: a new class of radiopharmaceutical for infection imaging. $\mathcal{F}$ Nucl Med 1993;34:119P.

10 Garner JS, Jarvis WR, Emori TG, et al. CDC definitions for nosocomial infections 1988. Am F Infect Control 1988;16: $128-40$.

11 Stokes EJ, Ridgeway GL. Antibiotic sensitivity tests. In: Stokes EJ, Ridgeway GL. Clinical microbiology. 6th ed. London: Edward Arnold, 1987:204-33.

12 Easmon CSF, Crane JP, Blowers A. Effect of ciprofloxacin on intracellular organisms: in-vitro and in-vivo studies. $\mathcal{f}$ Antimicrob Chemother 1986;18(suppl D):43-8. 